\title{
Enzyme Replacement Therapy for Murine Mucopolysaccharidosis Type VII
}

\author{
Mark S. Sands, " Carole Vogler," John W. Kyle," Jeffrey H. Grubb," Beth Levy," Nancy Galvin, " William S. Sly," and \\ Edward H. Birkenmeier* \\ *The Jackson Laboratory, Bar Harbor, Maine 04609; ${ }^{*}$ Department of Pathology, "The Edward A. Doisy Department of Biochemistry \\ and Molecular Biology, St. Louis University School of Medicine, St. Louis, Missouri 63104; and \$ Department of Medicine/Cardiology, \\ The University of Chicago, Chicago, Illinois 60637
}

\begin{abstract}
Recombinant mouse $\beta$-glucuronidase administered intravenously to newborn mice with mucopolysaccharidosis type VII (MPS VII) is rapidly cleared from the circulation and localized in many tissues. Here we determine the tissue distribution of injected enzyme and describe its effects on the histopathology in 6-wk-old MPS VII mice that received either one injection of $28,000 \mathrm{U}$ recombinant $\beta$-glucuronidase at 5 wk of age or received six injections of $28,000 \mathrm{U}$ given at weekly intervals beginning at birth. These mice were compared with untreated 6-wk-old MPS VII mice. The single injection decreased lysosomal distention in the fixed tissue macrophage system. MPS VII mice that received multiple injections had 27.8, 3.5, and $3.3 \%$ of normal levels of $\beta$-glucuronidase in liver, spleen, and kidney, respectively. Brain had detectable $\beta$-glucuronidase, ranging from 2.0-12.1\% of normal. Secondary elevations of $\alpha$ galactosidase and $\beta$-hexosaminidase in brain, spleen, liver, and kidney were decreased compared with untreated MPS VII mice. Although no improvement was observed in chondrocytes, glia, and some neurons, the skeleton had less clinical and pathological evidence of disease and the brain had reduced lysosomal storage in meninges and selected neuronal groups. These data show that recombinant $\beta$-glucuronidase treatment begun in newborn MPS VII mice provides enzyme to most tissues and significantly reduces or prevents the accumulation of lysosomal storage during the first 6 wk of life. Whether therapy begun later in life can achieve this level of correction remains to be established. (J. Clin. Invest. 1994.93:2324-2331.) Key words: $\beta$-glucuronidase • Sly syndrome $\bullet$ animal models $・$ lysosomal storage diseases $\bullet$ central nervous system
\end{abstract}

\section{Introduction}

Animal models of lysosomal storage disease have been used to test the efficacy of novel therapies for these diseases (1-3). Treatments have included bone marrow transplantation (BMT), ${ }^{1}$ somatic cell gene therapy and enzyme replacement (4-13). Mice homozygous for a frameshift mutation in the

Address correspondence to E. H. Birkenmeier, M.D., Senior Staff Scientist, The Jackson Laboratory, 600 Main St., Bar Harbor, ME 04609.

Received for publication 23 November 1993 and in revised form 18 February 1994.

1. Abbreviations used in this paper: BMT, bone marrow transplantation; FTMS, fixed tissue macrophage system; Man 6-P, mannose 6-phosphate; MPS, mucopolysaccharidosis.

J. Clin. Invest.

(C) The American Society for Clinical Investigation, Inc.

0021-9738/94/06/2324/08 $\$ 2.00$

Volume 93, June 1994, 2324-2331 $\beta$-glucuronidase gene, Gus, (14) have murine mucopolysaccharidosis type VII (MPS VII) $(1,2)$ and share many biochemical, pathological, and clinical features with human MPS VII (Sly Syndrome) (15). An increased life span and reduction in lysosomal storage in many tissues was observed in MPS VII mice after BMT (4). Newborn mice pretreated with low-dose radiation followed by BMT showed improved skeletal development and had $\beta$-glucuronidase positive cells in the brain (5). A reduction of lysosomal storage was also observed in the liver and spleen of MPS VII mice receiving retroviral mediated somatic cell gene therapy (9-11). Although BMT therapies correct or prevent lysosomal storage, they require pretreatment with irradiation to ensure transplant engraftment. Treatment of newborns with BMT, although effective, is accompanied by radiation dose-dependent cerebellar and retinal dysplasia and long bone growth retardation (5). A method of delivering enzyme that did not require irradiating young animals might allow reduction in lysosomal storage without the side effects observed with BMT.

Since the mannose receptor is expressed on the surface of tissue macrophages, purified glucocerebrosidase enzymatically modified in vitro to expose mannosyl residues (16) is targeted to the fixed tissue macrophage system (FTMS). Although a recent report showed that only a small fraction of the currently licensed enzyme was actually targeted to macrophages (17), intravenous administration of modified glucocerebrosidase is effective in reversing some of the clinical symptoms of Gaucher's disease, a lysosomal storage disease affecting the FTMS $(12,13,18)$. Other lysosomal storage diseases such as MPS VII, which affect many types of tissues, will require delivery of the enzyme to many other sites besides the FTMS. It seemed likely that tissues with cells expressing the mannose 6-phosphate (Man 6-P) receptor on their surfaces might be corrected by enzyme bearing the Man 6-P recognition marker.

Recently, Grubb et al. (19) developed a novel method for the production of large quantities of recombinant $\beta$-glucuronidase, a glycoprotein containing oligosaccharides having both the mannose and Man 6-P receptor recognition moieties. When recombinant enzyme was administered intravenously to newborn MPS VII mice, it was rapidly cleared from the circulation. High levels were detected in many tissues including the brain and FTMS (20). Enzyme localization in tissues correlated with the expression of Man 6-P receptor (21-23). The $t_{1 / 2}$ of the recombinant enzyme in various tissues was $1.2-4.2 \mathrm{~d}$, similar to that reported for infused human placental $\beta$-glucuronidase in rat tissue $(24,25)$. The high levels of enzyme achieved and the persistence of enzyme in tissues suggests that recombinant enzyme may be effective in treating murine MPS VII.

In this study, we describe the clinical, biochemical, histochemical, and pathological responses to six weekly infusions of recombinant $\beta$-glucuronidase begun in the neonatal period. 
These results are compared with those obtained 1 wk after a single infusion at $5 \mathrm{wk}$ of age.

\section{Methods}

Animals. Homozygous mutant (gus ${ }^{m p s} / g u s^{m p s}$ ) and phenotypically normal (+/?) mice were obtained from B6.C- $H-2^{b m l} /$ ByBir-gus ${ }^{m p s} /+$ mutant strain maintained by E. H. Birkenmeier at The Jackson Laboratory (1). Animals for this study were from either a pedigreed colony, maintained by strict brother-sister matings, or a nonpedigreed colony, maintained by crossing heterozygotes obtained from the pedigreed colony. The offspring were never more than one generation from the pedigreed colony. Homozygous mutants and normals $(+/+)$ were distinguished from heterozygotes $\left(+/ g u s^{m p s}\right)$ at birth using a fluorometric assay (26) to determine the level of $\beta$-glucuronidase activity in a sample of tissue obtained by toe clipping. Animals were observed weekly for phenotypic evidence of MPS VII.

Enzyme production and purification. Man 6-P receptor deficient mouse $L$ cells (27) which secrete $\sim 70 \%$ of lysosomal enzymes with the phosphomannosyl recognition marker were stably transfected with an expression plasmid containing the mouse $\beta$-glucuronidase cDNA ( 19 , 28 ). $\beta$-glucuronidase was purified from the conditioned media by ammonium sulfate precipitation, sephadex, and ion exchange chromatography (19). The purified enzyme $\left(2 \times 10^{6} \mathrm{U} / \mathrm{mg}\right)$ was diluted in 10 $\mathrm{mM}$ Tris, $\mathrm{pH} 7.5,150 \mathrm{mM} \mathrm{NaCl}$ and $1 \mathrm{mM} \beta$-glycerophosphate to a concentration of $2.8 \times 10^{5} \mathrm{U} / \mathrm{ml}$ and stored at $-70^{\circ} \mathrm{C}$. $\beta$-glucuronidase activity units are nanomoles of substrate hydrolyzed per hour.

Enzyme injections. Aliquots of enzyme were thawed and assayed immediately before injection. Five newborn $g u s^{m p s} / g u s^{m p s}$ mice were injected on the first day of life with $28,000 \mathrm{U}$ of enzyme in $100 \mu$ linto the superficial temporal vein. At 1 wk of age they received the same dose intraperitoneally followed by four injections into the tail vein at weekly intervals. The animals were killed at $6 \mathrm{wk}$ of age and tissues were analyzed for lysosomal enzyme activity and pathology. Two phenotypically normal mice were injected with enzyme on the same

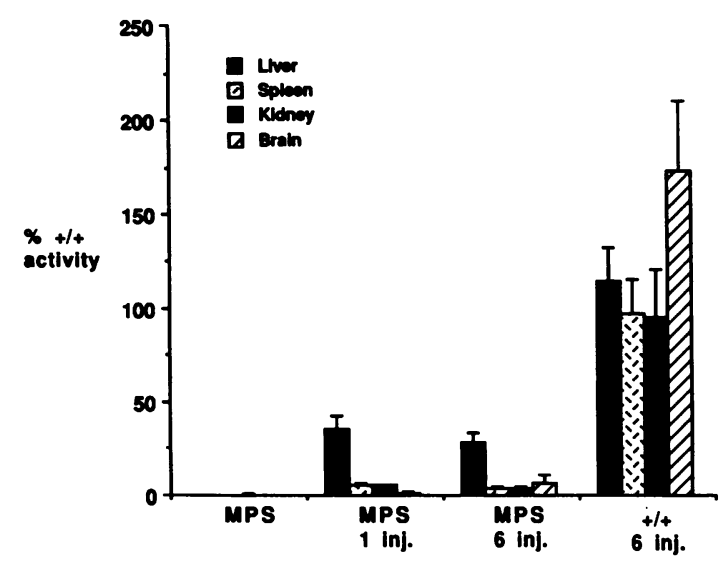

Figure 1. $\beta$-glucuronidase levels $1 \mathrm{wk}$ after injection. $\beta$-glucuronidase activity, expressed as percent of normal activity of $+/+$ mice, in liver, spleen, kidney, and brain $1 \mathrm{wk}$ after injection. Enzyme levels of two untreated mutant mice receiving six weekly injections of dilution buffer starting at birth (MPS) and two homozygous normal mice receiving the same regimen of enzyme injections $(+/+, 6$ inj. $)$ are shown. $\beta$-glucuronidase levels in MPS VII mice receiving a single enzyme injection at $5 \mathrm{wk}$ (MPS, $1 \mathrm{inj}$.) are compared to the enzyme levels in mutant mice receiving six weekly enzyme injections starting at birth (MPS, 6 inj.). Values for MPS, 1 inj. and MPS, 6 inj. are the average enzyme levels from five animals in each group. Error bars represent \pm 1 SD.
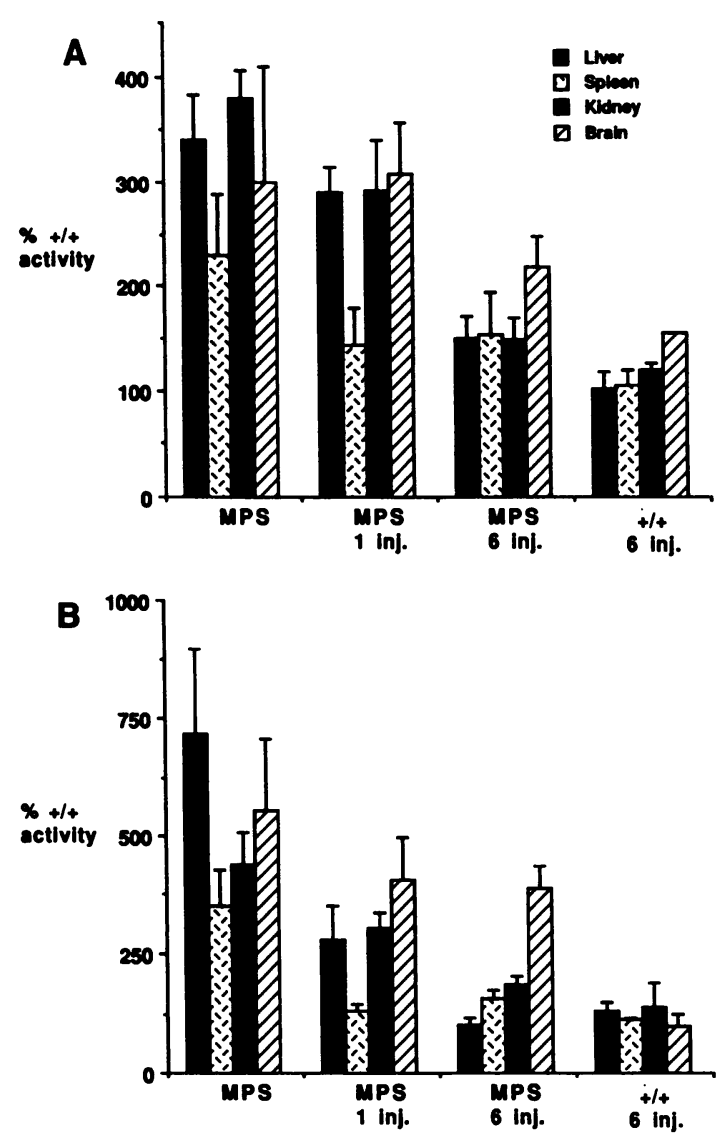

Figure 2. $\alpha$-galactosidase and $\beta$-hexosaminidase levels 1 wk after injection. $\alpha$-galactosidase $(A)$ and $\beta$-hexosaminidase $(B)$ activity is expressed as percent of $+/+$ activity in liver, spleen, kidney, and brain $1 \mathrm{wk}$ after the last injection. Enzyme levels from the same animals as described in Fig. 1 are shown and represent the average of two animals each from MPS and $+/+, 6$ inj. and the average of five animals each from MPS, 1 inj. and MPS, 6 inj. Error bars represent \pm 1 SD.

schedule as animals that received six injections. One mutant animal received six injections of dilution buffer starting at birth. Five additional mutant mice were injected via the tail vein with $28,000 \mathrm{U} \beta$-glucuronidase at $5 \mathrm{wk}$ of age, killed at $6 \mathrm{wk}$ of age, and analyzed biochemically and histochemically as described above. Two of these treated mutants were also studied histologically.

Biochemical analysis. Tissue sections were isolated and homogenized in $20 \mathrm{mM}$ Tris, pH 7.5, $140 \mathrm{mM} \mathrm{NaCl}, 10 \mathrm{mM} \beta$-mercaptoethanol and $0.25 \%$ saponin with a motorized pestle. Lysosomal enzymes were assayed fluorometrically using 4-methylumbelliferyl (4-MU) substrates $(10 \mathrm{mM})$ as previously described (26). $\beta$-glucuronidase, $\alpha$ galactosidase and $\beta$-hexosaminidase were assayed with the substrates 4-MU- $\beta$-D-glucuronide, 4-MU- $\alpha$-D-galactoside and 4-MU-N-acetyl- $\beta$ D-glucosaminide, respectively (Sigma Chemicals, St. Louis, MO). Protein determinations were performed by the Coomasie dye binding assay (29).

Pathology. Tissues were collected, fixed and prepared for light and electron microscopy as previously described (2). One MPS VII animal receiving six enzyme injections, one normal animal, and one MPS VII control were anesthetized and perfused through the left ventricle with $2 \%$ glutaraldehyde, $4 \%$ paraformaldehyde in PBS. Before perfusion, liver and spleen biopsies were obtained for histochemical and biochemical analysis. For histology, toluidine blue-stained, $1 / 2-\mu \mathrm{m}$-thick sections of tissue embedded in Spurr's resin were evaluated for lysosomal storage and selected tissues were also studied by electron microscopy. Eye, 

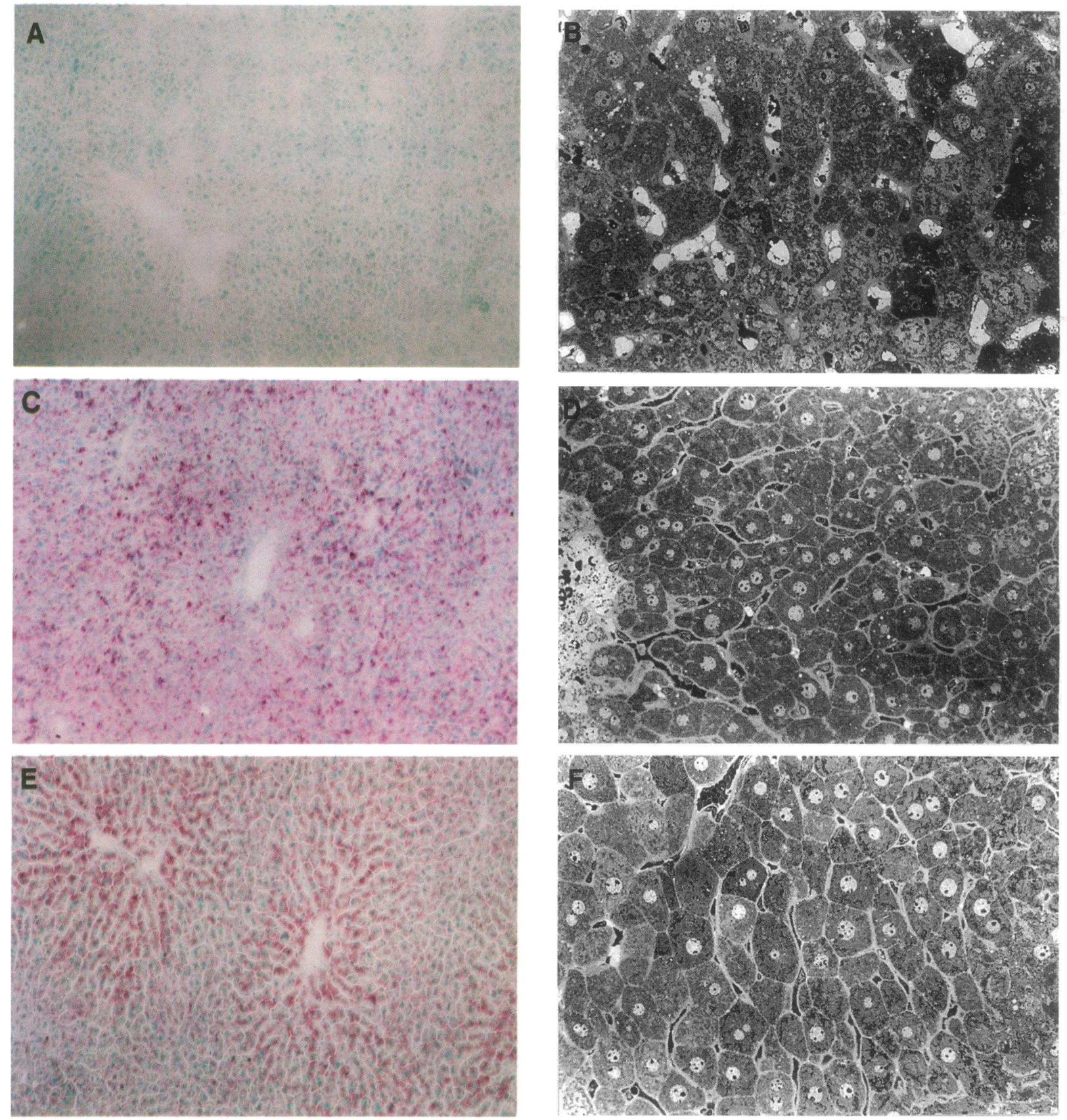

Figure 3. Liver response to enzyme replacement. $(A)$ Liver from an MPS VII mouse has no $\beta$-glucuronidase activity detectable by histochemical stain. ( $B$ ) Marked vacuolization of sinus lining cells is seen in an untreated mutant. $(C)$ After one injection of $28,000 \mathrm{U}$ recombinant $\beta$-glucuronidase, a mutant liver shows enzyme activity in an evenly dispersed nonzonal pattern. $(D)$ The sinus lining cells show a marked decrease in lysosomal distention even after a single injection of $\beta$-glucuronidase. $(E)$ After 6 wk of enzyme therapy, there is enzyme activity in Kupffer cells and hepatocytes and the enzyme is distributed in a zonal pattern with more activity in the central portion of the hepatic lobule than in the peripheral portion. $(F)$ The sinus lining cells show a marked decrease in lysosomal distention after six doses of $\beta$-glucuronidase. $(A, C$, and $E$ ) Naphthol-AS-BI- $\beta$-glucuronidase X62.5; $(B, D$, and $F)$ toluidine blue, X242.

rib, liver, kidney, spleen, heart, aorta, and a transverse section of the cerebrum including cerebral cortex, hippocampus, cerebellum, and leptomeninges were examined. Stifel joints were also examined after paraffin embedding and routine processing and staining with hematoxylin and eosin as well as with colloidal iron (2). Tissues from untreated mutant and normal mice from this and previous studies $(2,4,5)$ were used as histological controls.

$\beta$-glucuronidase was identified histochemically in unfixed frozen sections of rib, liver, spleen, kidney, heart, and brain using naphtholAS-BI- $\beta$-D-glucuronide and pararosaniline hydrochloride with a 3-h preincubation at $4^{\circ} \mathrm{C}$ in substrate alone and a $4-h$ incubation at $37^{\circ} \mathrm{C}$ in the presence of substrate and pararosaniline hydrochloride (30).

Morphometric analyses were performed on the femur, humerus, radius, ulna, tibia, and fibula from treated and untreated mice as previously described (5). Briefly, the long bones were excised, radiographed with a Hewlett Packard Faxitron specimen analyzer, and measured at their longest aspect. Bone lengths were then grouped and compared according to treatment and sex. The bone lengths for the treated group, represented as percent untreated normal, were averaged and analyzed using the Student's $t$ test of statistical significance. 

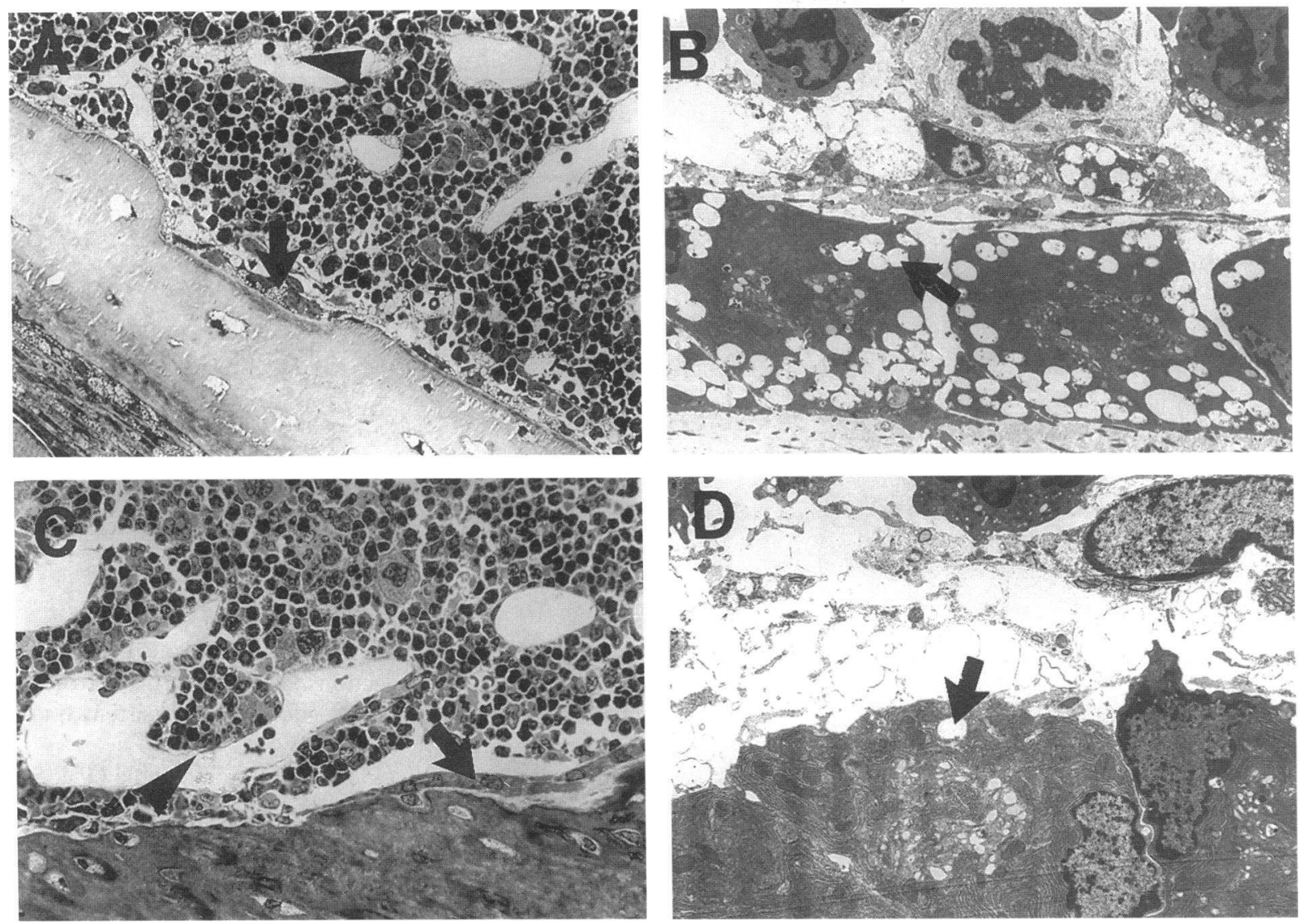

Figure 4. Osteoblast storage decreases after 6 wk enzyme therapy. ( $A$ and $B$ ) Osteoblasts (arrow) lining cortical bone in a mutant mouse contain numerous cytoplasmic vacuoles. Sinus lining cells (arrowhead) also contain a large number of distended lysosomes. $(C$ and $D$ ) After six doses of $\beta$-glucuronidase, osteoblasts (arrow) contain only a few small cytoplasmic vacuoles and sinus lining cells (arrowhead) show no evidence of lysosomal distention. $(A$ and $C$ ) Toluidine blue, X242, $(B)$ uranyl acetate, lead citrate, X2680; $(D)$ uranyl acetate, lead citrate, X3484.

\section{Results}

\section{Biochemical response of MPS VII mice to recombinant $\beta$ - glucuronidase}

Enzyme distribution. $1 \mathrm{wk}$ after the last injection, $\beta$-glucuronidase was detected in the liver, spleen, kidney, and brain of animals that received either single or multiple injections of enzyme (Fig. 1). The livers of animals that received a single injection had $35 \%$ of normal enzyme activity. Livers of animals that received multiple injections had $27.8 \%$ of normal enzyme activity. Spleens and kidneys had 3-5\% of normal levels of enzyme. The brains of animals receiving multiple injections had an average level of enzyme activity that was $6.7 \%$ of normal. However, in the brains of animals that received a single injection at $5 \mathrm{wk}$ of age, the average activity level was only $1 \%$ of normal $1 \mathrm{wk}$ after the injection. Except for the brain, the tissues from the two normal animals receiving multiple injections showed no detectable increases in $\beta$-glucuronidase activity. $\beta$-glucuronidase activity was not detected in the mutant animal injected with enzyme dilution buffer alone.

Secondary enzyme elevations. $\alpha$-galactosidase and $\beta$-hexosaminidase returned to near normal levels in the liver, spleen, and kidney of mutant mice receiving multiple injections (Fig. $2)$. There was a significant decrease in the levels of both enzymes $(P<0.05)$ in the brains of the mice from the multiple injection group. The spleens from animals injected with a sin- gle dose of enzyme also had nearly normal levels of $\alpha$-galactosidase and $\beta$-hexosaminidase. In contrast, the livers and kidneys showed only moderate decreases in the secondary elevations of $\alpha$-galactosidase and $\beta$-hexosaminidase in response to a single enzyme injection and the brain showed little or no change. As expected, the levels of $\alpha$-galactosidase and $\beta$-hexosaminidase in normal mice receiving six enzyme injections remained at normal levels (Fig. 2) and the mutant animal receiving six injections of dilution buffer without enzyme had secondary elevations similar to untreated mutant animals (data not shown).

\section{Reversal of lysosomal storage disease following enzyme replacement therapy}

Clinically, the MPS VII mice treated from birth with six enzyme injections were difficult to distinguish from normal mice at $6 \mathrm{wk}$ of age. They had nearly normal body weights and reduced facial dysmorphism (documented radiographically below). However, the mice receiving only a single enzyme injection at $5 \mathrm{wk}$ of age were phenotypically identical one wk later to untreated MPS VII mice of the same age.

Uninjected adult MPS VII mice had no histochemically detectable $\beta$-glucuronidase (Fig. $3 A$ ) and the cytoplasm of their Kupffer cells and the hepatocytes contained numerous distended lysosomes (Fig. $3 \mathrm{~B}$ ). $1 \mathrm{wk}$ after a single injection of enzyme, $\beta$-glucuronidase was detectable histochemically in the liver of mutant mice (Fig. $3 C$ ). The stain was more intense in 

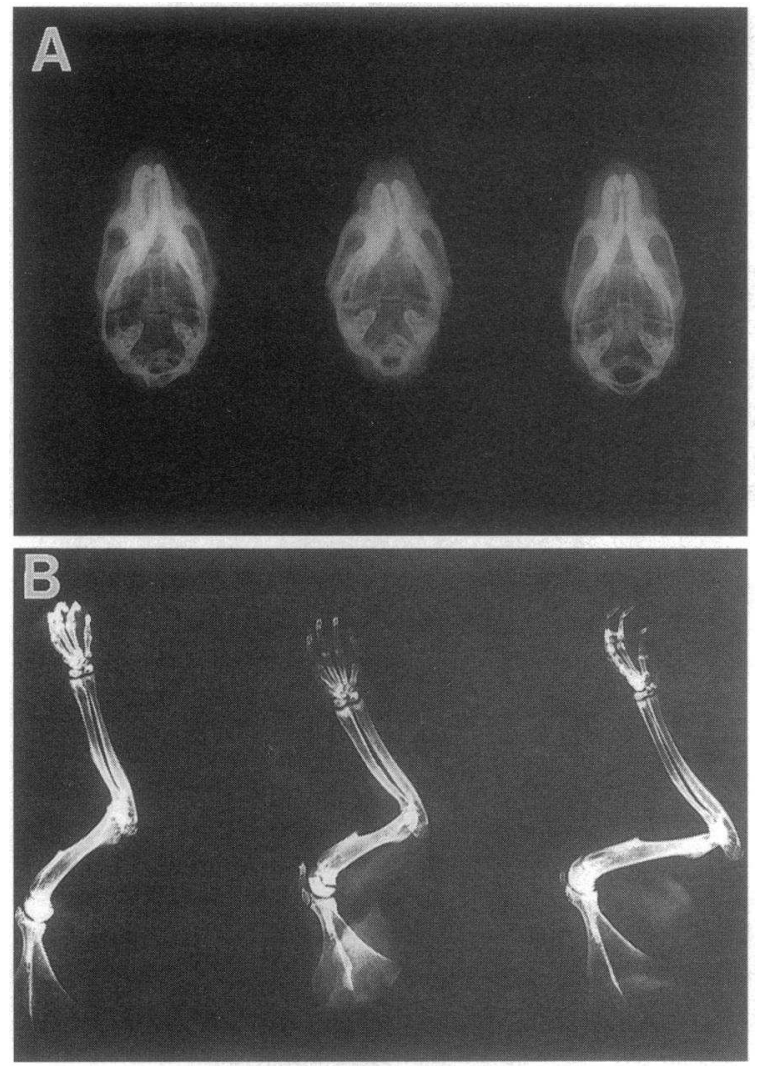

Figure 5. Improved radiographic changes after $\beta$-glucuronidase treatment. $(A)$ The skull from a mutant (middle) MPS VII mouse is easily distinguished from both a normal (right) and an enzyme treated MPS VII mouse (left). ( $B$ ) The length of the untreated MPS VII humerus and radius-ulna (middle) was shorter than that from the normal (right) and enzyme replaced MPS VII mouse (left).

Kupffer cells than in hepatocytes and was evenly distributed throughout the liver. Lysosomal distention was greatly reduced or absent in both hepatocytes and Kupffer cells of mice receiving only a single injection (Fig. $3 D$ ). The distribution of $\beta$-glucuronidase activity in the livers of animals receiving multiple injections over 5 wk was different from that observed in animals receiving one injection at $5 \mathrm{wk}$ of age. In multiply injected mice, $\beta$-glucuronidase was more apparent in hepatocytes than in Kupffer cells and central hepatocytes generally had more $\beta$-glucuronidase activity than those at the periphery of the lobule (Fig. $3 E$ ). Hepatic lysosomal distention was absent in mice that received multiple injections of enzyme (Fig. $3 F$ ). The spleens from both the singly and multiply injected MPS VII mice also showed marked clearing of lysosomal storage. In mice treated with multiple $\beta$-glucuronidase injections, interstitial cells in the heart and the kidney, glomerular visceral epithelial cells, and retinal pigment epithelium had less lysosomal storage than untreated MPS VII mice. However, $\beta$-glucuroni-
Table I. Central Nervous System Lysosomal Storage in MPS VII Mice

\begin{tabular}{lccc}
\hline & & \multicolumn{2}{c}{$\beta$-glucuronidase treatment } \\
\cline { 3 - 4 } & Untreated & One dose & Six doses \\
\hline Neurons & & & \\
Cerebral neocortex & $+++^{*}$ & +++ & $+-^{+}$ \\
Hippocampus & +++ & +++ & $+/-$ \\
Central grey matter & +++ & +++ & $+/-$ \\
Purkinje cells & +++ & +++ & +++ \\
Glia (nonependymal) & +++ & +++ & +++ \\
Ependyma & $+1-$ & $+/-$ & $+/-$ \\
Leptomeninges & +++ & +++ & $+/-$ \\
Vessels/perivascular cells & +++ & +++ & $+/-$ \\
& & & \\
\hline
\end{tabular}

* Marked lysosomal distention. ${ }^{\ddagger}$ Mild to absent storage material.

dase activity was not detected histochemically in the heart or kidney after six enzyme injections, and the corneal stromal fibroblasts and cells in the aortic media had persistent lysosomal storage.

There was microscopic (Fig. 4) and radiographic (Fig. 5) evidence of partial correction in bones after multiple enzyme injections. The osteoblasts lining the bone had less lysosomal distention as did the sinus lining cells, and bone marrow from the one mouse examined was positive for $\beta$-glucuronidase activity by histochemical stain. However, the chondrocytes contained distended lysosomes and were indistinguishable from those of untreated mutants and there was persistent articular storage. The bone length in MPS VII mice which received multiple injections was $88 \%$ of normal compared with $82 \%$ of normal in untreated mutants (data not shown). Radiographic evidence of MPS was also reduced in mice receiving six enzyme injections (Fig. 5). In contrast, mice receiving only a single injection of $\beta$-glucuronidase had bones indistinguishable from those of untreated MPS VII mice, except that the marrow sinus lining cells had reduced lysosomal storage. Within the brain, the ependyma, leptomeninges, perivascular cells, and specific neuronal groups had a decrease in lysosomal storage following the six weekly injections of recombinant $\beta$-glucuronidase (Fig. 6 ; Table I). However, Purkinje and glial cells contained persistent lysosomal storage indistinguishable from that observed in untreated MPS VII controls (Table I). All neuronal groups in the central nervous system of mice that received a single injection of enzyme at $5 \mathrm{wk}$ of age failed to show improvement in lysosomal storage ( Table I).

\section{Discussion}

We recently reported that recombinant $\beta$-glucuronidase was widely distributed in tissues of newborn MPS VII mice $1 \mathrm{~h}$ after

Figure 6. Reduction of lysosomal storage in the central nervous system after six enzyme injections. $(A$ and $B)$ The meninges from an untreated MPS VII mouse shows cytoplasmic vacuolization. ( $C$ and $D$ ) After six doses of enzyme, meningial fibroblasts, and perivascular cells had a marked reduction in lysosomal storage. ( $E$ and $F$ ) Neurons from an untreated MPS VII mouse show numerous cytoplasmic vacuoles. ( $G$ and $H$ ) After six $\beta$-glucuronidase injections, cytoplasmic vacuoles are markedly reduced in hippocampal neurons although glial storage persists. $(A)$ toluidine blue, X287; $(B$ and $D$ ) uranyl acetate, lead citrate, X2120; $(C)$ toluidine blue, X452; $(E)$ toluidine blue, X583; $(F)$ uranyl acetate, lead citrate, X2860; $(G)$ toluidine blue, X543; $(H)$ uranyl acetate, lead citrate, X2200. 
A

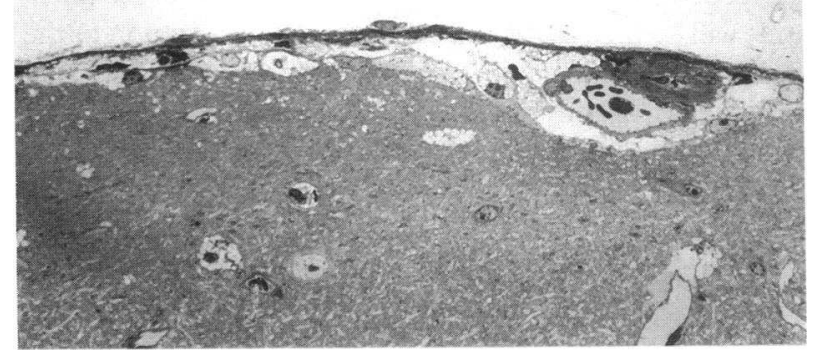

c)
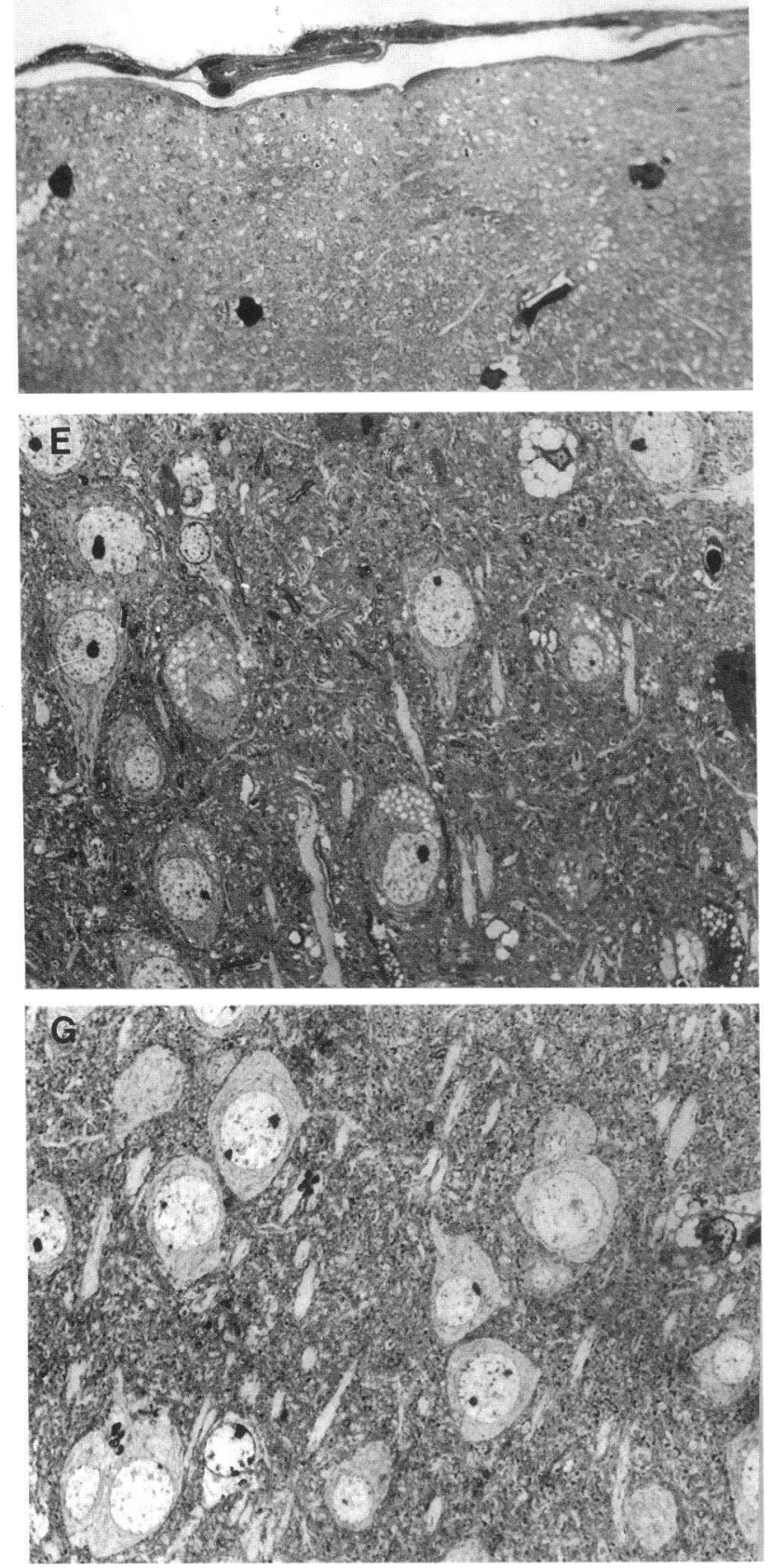

B
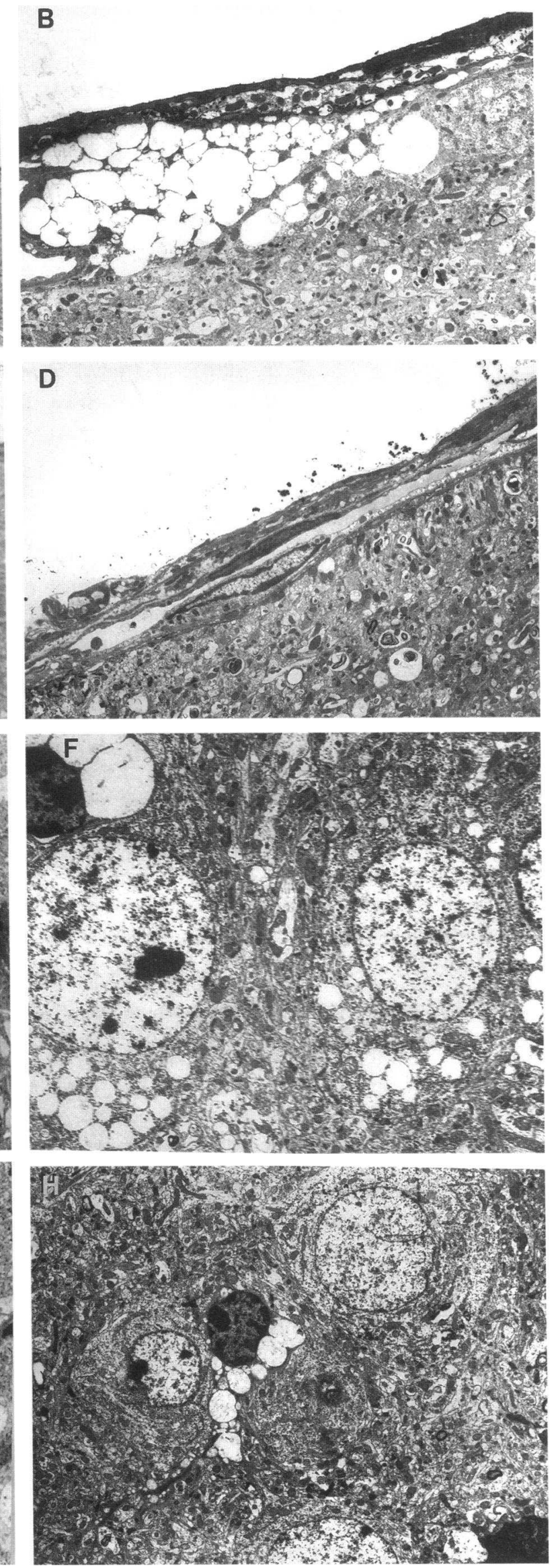
intravenous infusion (20). The distribution correlated generally with the distribution of the Man 6-P receptor. Especially striking were the observations that heart, liver, and brain had $23,13.5$, and 0.3 times, respectively, the levels of $\beta$-glucuronidase found in normal mice, and that bone had abundant histochemically demonstrable $\beta$-glucuronidase activity. The present study demonstrates that recombinant enzyme reaching these tissues has important therapeutic effects in preventing the accumulation of lysosomal storage and thereby delaying, if not preventing, the clinical consequences of $\beta$-glucuronidase deficiency.

We previously showed that BMT in young adult mice at 4-8 wk of age dramatically altered the clinical course of murine MPS VII, increasing life span from an average of 5 mo to an average of $18 \mathrm{mo}$, and correcting metabolic defects in liver, spleen, heart, cornea, and meninges (4). Skeletal improvement was not readily apparent, probably because bone disease was already well established at the time the adult animals received BMT. Also, in contrast to the results seen with enzyme replacement, no decrease in neuronal storage was observed after BMT. We subsequently studied the effects of BMT in newborn MPS VII mice (5). Tissue responses were at least as good as when BMT was given to adults, and the animals had less facial dysmorphism and other clinical signs of lysosomal storage disease compared to animals that received BMT later in life. However, the radiation used to ablate the newborn marrow had deleterious effects on development of the cerebellum and retina, and on the growth of long bones.

The extremely favorable response to enzyme therapy seen in the present study suggests that enzyme therapy may reach tissues that BMT does not. To achieve maximum levels of correction may require early administration of enzyme to reach these tissues during critical developmental stages early in life. In addition, because complete bone marrow engraftment takes 4-6 wk (31), enzyme replacement both prior to and immediately after transplantation may substantially improve the longterm therapeutic benefits of BMT.

These studies show that recombinant enzyme replacement therapy achieves improvements in the developing central nervous system that were not achieved by BMT in newborns or young adults. Several possible factors may contribute to this advantage of early enzyme therapy. First, the distribution of cell surface receptors which influence where enzyme localizes is known to be subject to developmental regulation (21-23). The Man 6-P receptor represents $0.1 \%$ of the total protein in fetal rat brain and falls 5-10-fold during postnatal development.

The second factor is that the blood/brain barrier may not be completely developed in the newborn mouse (32). This may provide intravascular $\beta$-glucuronidase access to cell surface receptors in the central nervous system that are not accessible subsequently. In addition, the relatively large dose in the newborn $(7 \mathrm{mg} / \mathrm{kg})$ may influence the distribution by mass action and by saturating competing receptors (e.g., the mannose receptor in the FTMS). In the experiments reported here, the amount of enzyme given at $5 \mathrm{wk}(28,000 \mathrm{U})$ was the same as the amount given to the newborn. Thus, compared to a newborn, the 5-wk-old received only $\sim 1 / 10$ th the dose per $\mathrm{kg}$ due to the large increase in weight with age.

The difference in distribution of $\beta$-glucuronidase in livers from singly or multiply injected MPS VII mice is also of interest. This may relate to differences in developmental regulation of various cell surface receptors in liver (e.g., the asialoglycoprotein receptor on hepatocytes (33), the mannose receptor on Kupffer cells $(24,25)$, and the Man 6-P receptor $(34,35)$ on both cell types), and might also be influenced by the changing weight-dependent dosage received over the course of the injections. It will be interesting to determine the distribution of the enzyme when a weight adjusted dose comparable to that given in the newborn is administered to the 5-wk-old adult animal.

While there are still questions to be answered about the optimum dose and regimen for enzyme injections, the general conclusion from these studies is that enzyme therapy for MPS VII beginning in the newborn period is extremely encouraging. It is now important to compare the long-term effects of enzyme replacement on survival and clinical course in animals receiving enzyme therapy as a sole treatment, or in combination with BMT, to the favorable clinical responses reported for BMT alone.

\section{Acknowledgments}

We thank Dr. Jane Barker for helpful discussions throughout the study and Aletha Torrey and Ann Higgins for excellent technical assistance.

This work was supported by National Institutes of Health grants DK-41082 to E. H. Birkenmeier and C. Vogler, DK-40163 and GM34182 to W. S. Sly, and National Research Service Award grants DK08546 and DK-07449 to M. S. Sands. The Jackson Laboratory is fully accredited by the American Association for Accreditation of Laboratory Animal Care.

\section{References}

1. Birkenmeier, E. H., M. T. Davisson, W. G. Beamer, R. E. Ganschow, C. A. Vogler, B. Gwynn, K. A. Lyford, L. M. Maltais, and C. J. Wawrzyniak. 1989. Murine mucopolysaccharidosis type VII: characterization of a mouse with $\beta$-glucuronidase deficiency. J. Clin. Invest. 83:1258-1266.

2. Vogler, C., E. H. Birkenmeier, W. S. Sly, B. Levy, C. Pegors, J. W. Kyle, and W. G. Beamer. 1990. A murine model of mucopolysaccharidosis type VII: gross and microscopic findings in $\beta$-glucuronidase-deficient mice. Am. J. Pathol. 136:207-217.

3. Haskins, M. E., R. J. Desnick, N. DiFerrante, P. F. Jezyk, and D. F. Patterson. 1984. $\beta$-glucuronidase deficiency in a dog: a model of mucopolysaccharidosis type VII. Pediatr. Res. 18:980-984.

4. Birkenmeier, E. H., J. E. Barker, C. A. Vogler, J. W. Kyle, W. S. Sly, B. Gwynn, B. Levy, and C. Pegors. 1991. Increased life span and correction of metabolic defects in murine mucopolysaccharidosis type VII after syngeneic bone marrow transplantation. Blood. 78:3081-3092.

5. Sands, M. S., J. E. Barker, C. A. Vogler, B. Levy, B. Gwynn, N. Galvin, W. S. Sly, and E. H. Birkenmeier. 1993. Treatment of murine mucopolysaccharidosis type VII by syngeneic bone marrow transplantation in neonates. $\mathrm{Lab}$. Invest. 68:676-686.

6. Hoogerbrugge, P. M., B. J. H. M. Poorthius, A. E. Romme, J. J. P. van de Kamp, G. Wagemaker, and D. W. van Bekkum. 1988. Effect of bone marrow transplantation on enzyme levels and clinical course in the neurologically affected twitcher mouse. J. Clin. Invest. 81:1790-1794.

7. Yeager, A. M., S. Brennan, C. Tiffany, H. W. Moser, and G. W. Santos. 1984. Prolonged survival and remyelination after hematopoietic cell transplantation in the twitcher mouse. Science (Wash. DC). 225:1052-1054.

8. Shull, R. M., N. E. Hastings, R. R. Selcer, J. B. Jones, J. R. Smith, W. C. Cullen, and G. Constantopoulos. 1987. Bone marrow transplantation in canine mucopolysaccharidosis I. J. Clin. Invest. 79:435-443.

9. Wolfe, J. H., M. S. Sands, J. E. Barker, B. Gwynn, L. B. Rowe, C. A. Vogler, and E. H. Birkenmeier. 1992. Reversal of pathology in murine mucopolysaccharidosis type VII by somatic cell gene transfer. Nature (Lond.). 360:749-753.

10. Moullier, P., D. Bohl, J. M. Heard, and O. Danos. 1993. Correction of lysosomal storage in the liver and spleen of MPS VII mice by implantation of genetically modified skin fibroblasts. Nature Genet. 4:154-159.

11. Marechal, V., N. Naffakh, O. Danos, and J. M. Heard. 1993. Disappearance of lysosomal storage in spleen and liver of mucopolysaccharidosis VII mice after transplantation of genetically modified bone marrow stem cells. Blood. 82:1358-1365.

12. Beutler, E., A. Kay, A. Saven, P. Garver, D. Thurston, A. Dawson, and B. 
Rosenbloom. 1991. Enzyme replacement therapy for Gaucher's disease. Blood. 78:1183-1189.

13. Barton, N. W., R. O. Brady, J. M. Dambrosia, A. M. Di Bisceglie, S. H. Doppelt, S. C. Hill, H. J. Mankin, G. J. Murray, R. I. Parker, C. E. Argoff, R. P. Grewal, K. T. Yu, and Collaborators. 1991. Replacement therapy for inherited enzyme deficiency-macrophage targeted glucocerebrosidase for Gaucher's disease. $N$. Engl. J. Med. 324:1464-1470.

14. Sands, M. S., and E. H. Birkenmeier. 1993. A single-base-pair deletion in the $\beta$-glucuronidase gene accounts for the phenotype of murine mucopolysaccharidosis type VII. Proc. Natl. Acad. Sci. USA. 90:6567-6571.

15. Sly, W. S., B. A. Quinton, W. H. McAlister, and D. L. Rimoin. 1973. $\beta$-glucuronidase deficiency: report of clinical, radiologic and biochemical features of a new mucopolysaccharidosis. J. Pediatr. 82:249-257.

16. Doebber, T. W., M. S. Wu, R. L. Bugianesi, M. M. Ponpipom, F. S. Furbish, J. A. Barranger, R. O. Brady, and T. Y. Shen. 1982. Enhanced macrophage uptake of synthetically glycosylated human placental $\beta$-glucuronidase. $J$. Biol. Chem. 257:2193-2199.

17. Sato, Y., and E. Beutler. 1993. Binding, internalization, and degradation of mannose-terminated glucocerebrosidase by macrophages. J. Clin. Invest. 91:1909-1917.

18. Barton, N. W., R. O. Brady, J. M. Dambrosia, S. H. Doppelt, S. C. Hill, C. A. Holder, H. J. Mankin, G. J. Murray, G. C. Zirzow, and R. I. Parker. 1992. Dose-dependent response to macrophage-targeted glucocerebrosidase in a child with Gaucher disease. J. Pediatr. 120:277-280.

19. Grubb, J. H., J. W. Kyle, L. B. Cody, and W. S. Sly. 1993. Large scale purification in phosphorylated recombinant human $\beta$-glucuronidase from overexpressing mouse L cells. FASEB (Fed. Am. Soc. Exp. Biol.) J. 7:1255a. (Abstr.)

20. Vogler, C., M. Sands, A. Higgins, B. Levy, J. Grubb, E. H. Birkenmeier, and W.S. Sly. 1993. Enzyme replacement with recombinant $\beta$-glucuronidase in the newborn mucopolysaccharidosis type VII mouse. Pediatr. Res. 34:837-840.

21. Sklar, M. M., W. Kiess, C. L. Thomas, and S. P. Nissley. 1989. Developmental expression of the tissue insulin-like growth factor II/mannose 6-phosphate receptor in the rat. J. Biol. Chem. 264:16733-16738.

22. Senior, P. V., S. Byrne, W. J. Brammar, and F. Beck. 1990. Expression of the IGF II/mannose 6-phosphate receptor mRNA and protein in the developing rat. Development (Camb.). 109:67-73.

23. Matzner, U., K. Von Figura, and R. Pohlmann. 1992. Expression of the two mannose 6-phosphate receptors is spatially and temporally different during mouse embryogenesis. Development (Camb.). 114:965-972.
24. Achord, D., F. Brot, A. Gonzalez-Noriega, W. Sly, and P. Stahl. 1977. Human $\beta$-glucuronidase. II. Fate of infused human placental $\beta$-glucuronidase in the rat. Pediatr. Res. 11:816-822.

25. Achord, D., F. E. Brot, C. E. Bell, and W. S. Sly. 1978. Human $\beta$-glucuronidase: in vivo clearance and in vitro uptake by a glycoprotein recognition system on reticuloendothelial cells. Cell. 15:269-278.

26. Fischer, H. D., A. Gonzalez-Noriega, and W. S. Sly. 1980. $\beta$-glucuronidase binding to human fibroblast membrane receptors. J. Biol. Chem. 255:50695074.

27. Gabel, C. A., D. E. Goldberg, and S. Kornfeld. 1983. Identification and characterization of cells deficient in the mannose 6-phosphate receptor: evidence for an alternate pathway for lysosomal enzyme targeting. Proc. Natl. Acad. Sci. USA. 80:775-779.

28. Watson, G., M. Felder, L. Rabinow, K. Moore, C. Labarca, C. Tietze, G. Vander Molen, L. Bracey, M. Brabant, J. Cai, and K. Paigen. 1985. Properties of rat and mouse $\beta$-glucuronidase mRNA and cDNA, including evidence for sequence polymorphism and genetic regulation of mRNA levels. Gene (Amst.). 36:15-25.

29. Bradford, M. M. 1976. A rapid and sensitive method for the quantitation of microgram quantities of protein utilizing the principle of protein dye binding. Anal. Biochem. 72:248-254.

30. Wolfe, J. H., E. H. Schuchman, L. E. Stramm, E. A. Concaugh, M. E Haskins, G. D. Aguirre, D. F. Patterson, R. J. Desnick, and E. Gilboa. 1990 Restoration of normal lysosomal function in mucopolysaccharidosis type VIl cells by retroviral vector-mediated gene transfer. Proc. Natl. Acad. Sci. USA. 87:2877-2881

31. Barker, J. E., and E. McFarland. 1985. The hematopoietic stem cells of $\alpha$-thalassemic mice. Blood. 66:595-601.

32. Laterra, J. J., P. A. Stewart, and G. W. Goldstein. 1992. Development of the blood brain barrier. In Fetal and Neonatal Physiology. A. Polin, and W. W. Fox, editors. W. B. Saunders Co., Philadelphia, PA. 1525-1531.

33. Wall, D., G. Wilson, and A. L. Hubbard. 1980. The galactose-specific recognition system of mammalian liver: the route of ligand internalization in rat hepatocytes. Cell. 21:79-93.

34. Kaplan, A., D. T. Achord, and W. S. Sly. 1977. Phosphohexosyl components of a lysosomal enzyme are recognized by pinocytosis receptors on human fibroblasts. Proc. Natl. Acad. Sci. USA. 74:2026-2030.

35. Kornfeld, S. 1992. Structure and function of the mannose 6-phosphate/ insulin like growth factor II receptors. Annu. Rev. Biochem. 61:307-330. 